\title{
KRAS NM_004985.3:c.35G>T
}

National Cancer Institute

\section{Source}

National Cancer Institute. KRAS NM 004985.3:C.35G>T. NCI Thesaurus. Code C98392.

A nucleotide substitution at position 35 of the coding sequence of the KRAS gene where guanine has been mutated to thymine. 